June - 2007

\title{
Defining, Discussing, and Evaluating Mobile Learning: The moving finger writes and having writ.... .
}

\author{
John Traxler \\ University of Wolverhampton, UK
}

\begin{abstract}
Since the start of the current millennium, experience and expertise in the development and delivery of mobile learning have blossomed and a community of practice has evolved that is distinct from the established communities of 'tethered' e-Learning. This community is currently visible mainly through dedicated international conference series, of which MLEARN is the most prestigious, rather than through any dedicated journals. So far, these forms of development and delivery have focussed on short-term small-scale pilots and trials in the developed countries of Europe, North America, and the Pacific Rim, and there is a taxonomy emerging from these pilots and trials that suggests tacit and pragmatic conceptualisations of mobile learning.
\end{abstract}

What has, however, developed less confidently within this community is any theoretical conceptualisation of mobile learning and with it any evaluation methodologies specifically aligned to the unique attributes of mobile learning.

Some advocates of mobile learning attempt to define and conceptualise it in terms of devices and technologies; other advocates define and conceptualise it in terms of the mobility of learners and the mobility of learning, and in terms of the learners' experience of learning with mobile devices.

The role of theory is, perhaps, a contested topic in a community that encompasses philosophical affiliations from empiricists to post-structuralists, each with different expectations about the scope and legitimacy of theory in their work. The mobile learning community may nevertheless need the authority and credibility of some conceptual base.

Such a base would provide the starting point for evaluation methodologies grounded in the unique attributes of mobile learning. Attempts to develop the conceptualisations and evaluation of mobile learning, however, must recognise that mobile learning is essentially personal, contextual, and situated; this means it is 'noisy' and this is problematic both for definition and for evaluation.

Furthermore, defining mobile learning can emphasise those unique attributes that position it within informal learning, rather than formal. These attributes place much mobile learning at odds with formal learning with its cohorts, courses, semesters, assessments, and campuses, and with its monitoring and evaluation regimes. This raises concerns for the nature of any large-scale and 
Defining, Discussing, and Evaluating Mobile Learning

Traxler

sustained deployment and the extent to which the unique attributes of mobile learning may be lost or compromised.

Looking at mobile learning in a wider context, we have to recognise that mobile, personal, and wireless devices are now radically transforming societal notions of discourse and knowledge, and are responsible for new forms of art, employment, language, commerce, deprivation, and crime, as well as learning. With increased popular access to information and knowledge anywhere, anytime, the role of education, perhaps especially formal education, is challenged and the relationships between education, society, and technology are now more dynamic than ever.

The paper explores and articulates these issues and the connections between them specifically in the context of the wider and sustained development of mobile learning.

Keywords: Mobile learning; distance learning; definition; conceptualisation; evaluation

\section{Introduction}

The use of wireless, mobile, portable, and handheld devices are gradually increasing and diversifying across every sector of education, and across both the developed and developing worlds. It is gradually moving from small-scale, short-term trials to larger more sustained and blended deployment. This article draws on recent publications, projects, and trials in order to explore the possible future and nature of mobile education. The article then examines the relationship between the challenges of rigorous and appropriate evaluation of mobile education and the challenges of embedding and mainstreaming mobile education within formal institutional education.

Mobile learning has growing visibility and significance in higher education. Evidence for this growing visibility and significance is as follows. First, there is the growing size and frequency of dedicated conferences, seminars, and workshops, both in the United Kingdom and internationally. The first of the MLEARN series, MLEARN 2002 in Birmingham, for example, was followed by MLEARN 2003 in London, with more than 200 delegates from 13 countries, by MLEARN 2004 in Rome in July 2004, by MLEARN 2005 in Cape Town in October 2005, and by MLEARN 2006 in Banff, Alberta in November 2006. Another dedicated event, the International Workshop on Mobile and Wireless Technologies in Education (WMTE, 2002), sponsored by IEEE, took place in Sweden in August 2002 (http://ttf.ieee.org/wmte2002/). The second WMTE (http://ttf.ieee.org/wmte2003/) was held at National Central University in Taiwan in March 2004, in Japan in 2005, and in Athens in 2006. Both these series report buoyant attendance. There are also a growing number of national and international workshops. The June 2002 national workshop in Telford on mobile learning in the computing discipline attracted 60 delegates from UK higher education (http://www.ics.ltsn.ac.uk/events). The National Workshop and Tutorial on Handheld Computers in Universities and Colleges at Telford (http://www.einnovationcentre.co.uk/eic event.htm ) on June 11, 2004, and subsequent events on January 12, 2005 and November 4, 2005 (http://www.aidtech.wlv.ac.uk) all attracted over 90 delegates. The International Association for Development of the Information Society (IADIS) (www.IADIS.org) now run a conference series, the first taking place in Malta in 2005, the second in Dublin in 2006, and the third in Lisbon in 2007. Secondly, there have also been a rising number of references to mobile learning at generalist academic conferences, for example the Association for Learning Technology conference (ALT-C) every September in the UK (http://www.alt.ac.uk). 
Defining, Discussing, and Evaluating Mobile Learning

Traxler

The mobile learning currently exploits both handheld computers and mobile telephones and other devices that draw on the same set of functionalities. Mobile learning using handheld computers is obviously relatively immature in terms of both its technologies and its pedagogies, but is developing rapidly. It draws on the theory and practice of pedagogies used in technology enhanced learning and others used in the classroom and the community, and takes place as mobile devices are transforming notions of space, community, and discourse (Katz \& Aakhus, 2002; Brown \& Green, 2001) and the investigative ethics and tools (Hewson, Yule, Laurent, \& Vogel, 2003). The term covers the personalised, connected, and interactive use of handheld computers in classrooms (Perry, 2003; O’Malley \& Stanton, 2002), in collaborative learning (Pinkwart, Hoppe, Milrad, \& Perez, 2003), in fieldwork (Chen, Kao, \& Sheu, 2003), and in counselling and guidance (Vuorinen \& Sampson, 2003). Mobile devices are supporting corporate training for mobile workers (Gayeski, 2002; Pasanen, 2003; Lundin \& Magnusson, 2003) and are enhancing medical education (Smordal \& Gregory, 2003), teacher training (Seppala \& Alamaki, 2003), music composition (Polishook, 2005), nurse training (Kneebone, 2005), and numerous other disciplines. They are becoming a viable and imaginative component of institutional support and provision (Griswold, Boyer, Brown, et al., 2002; Sariola, 2003; Hackemer \& Peterson, 2005). In October 2005, the first comprehensive handbook of mobile learning was published (KukulskaHulme \& Traxler, 2005), but accounts of mobile distance learning are still infrequent.

There are now a large number of case studies documenting trials and pilots in the public domain (Kukulska-Hulme \& Traxler, 2005; JISC, 2005; Attewell \& Savill-Smith, 2004). In looking at these, we can see some categories of mobile learning emerging (Kukulska-Hulme \& Traxler, in press):

- Technology-driven mobile learning - Some specific technological innovation is deployed in an academic setting to demonstrate technical feasibility and pedagogic possibility

- Miniature but portable e-Learning - Mobile, wireless, and handheld technologies are used to re-enact approaches and solutions already used in 'conventional' e-Learning, perhaps porting some e-Learning technology such as a Virtual Learning Environment (VLE) to these technologies or perhaps merely using mobile technologies as flexible replacements for static desktop technologies

- Connected classroom learning - The same technologies are used in classroom settings to support collaborative learning, perhaps connected to other classroom technologies such as interactive whiteboards

- Informal, personalised, situated mobile learning - The same technologies are enhanced with additional functionality, for example location-awareness or video-capture, and deployed to deliver educational experiences that would otherwise be difficult or impossible

- Mobile training/ performance support - The technologies are used to improve the productivity and efficiency of mobile workers by delivering information and support justin-time and in context for their immediate priorities (for an early account, see Gayeski, 2002)

- Remote/ rural/ development mobile learning - The technologies are used to address environmental and infrastructural challenges to delivering and supporting education 
Defining, Discussing, and Evaluating Mobile Learning

Traxler

where 'conventional' e-Learning technologies would fail, often troubling accepted developmental or evolutionary paradigms

Mobile distance learning could fall into any of these categories (with the exception of the 'connected classroom learning'); how it develops will depend in part on the affordances of any given situation. These affordances might include:

- Infrastructure, meaning power supply, postal services, Internet connectivity, etc.

- Sparsity, giving rise to infrequent face-to-face contact, lack of technical support, etc.

- The wider policy agenda including lifelong learning, inclusion (of rural areas for example), assistivity, participation, and access

- Mobile distance learning within a framework of blended distance learning and the affordances of other delivery and support mechanisms

\section{Defining Mobile Education}

In spite of the activity cited above, the concept of mobile education or mobile learning is still emerging and still unclear. How it is eventually conceptualised will determine perceptions and expectations, and will determine its evolution and future. There are different stakeholders and factors at work in this process of conceptualising mobile education and the outcome is uncertain.

There are obviously definitions and conceptualisations of mobile education that define it purely in terms of its technologies and its hardware, namely that it is learning delivered or supported solely or mainly by handheld and mobile technologies such as personal digital assistants (PDAs), smartphones or wireless laptop PCs. These definitions, however, are constraining, techno-centric, and tied to current technological instantiations. We, therefore, should seek to explore other definitions that perhaps look at the underlying learner experience and ask how mobile learning differs from other forms of education, especially other forms of e-Learning.

If we take as our starting point the characterisations of mobile learning found in the literature (the conference proceedings from MLEARN and WMTE for example), we find words such as 'personal,' 'spontaneous,' 'opportunistic,' 'informal,' 'pervasive,' 'situated,' 'private,' 'context-aware,' 'bite-sized,' and 'portable.' This is contrasted with words from the literature of conventional 'tethered' e-Learning such as 'structured,' 'media-rich,' 'broadband,' 'interactive,' 'intelligent,' and 'usable.' We can use these two lists to make a blurred distinction between mobile learning and eLearning. This distinction, however, is not only blurred but in part is also only temporary. Many of the virtues of e-Learning are the virtues of the power of its technology (and the investment in it) and soon these virtues will also be accessible to mobile devices as market forces drive improvements in interface design, processor speed, battery life, and connectivity bandwidth. Nevertheless, this approach underpins a conceptualisation of mobile learning in terms of the learners' experiences and an emphasis on 'ownership,' informality, mobility, and context that will always be inaccessible to conventional 'tethered' e-Learning.

Tackling the problem of definition from another direction, we see that mobile devices and technologies are pervasive and ubiquitous in many modern societies, and are increasingly changing the nature of knowledge and discourse in these societies (whilst being themselves the products of various social and economic forces). This, in turn, alters both the nature of learning 
(both formal and informal) and alters the ways that learning can be delivered. Learning that used to be delivered 'just-in-case,' can now be delivered 'just-in-time,' 'just enough,' and 'just-for-me.' Finding information rather than possessing it or knowing it becomes the defining characteristic of learning generally and of mobile learning especially, and this may take learning back into the community.

Mobile technologies also alter the nature of work (the driving force behind much education and most training), especially of knowledge work. Mobile technologies alter the balance between training and performance support, especially for many knowledge workers. This means that 'mobile' is not merely a new adjective qualifying the timeless concept of 'learning'- 'mobile learning' is emerging as an entirely new and distinct concept alongside the 'mobile workforce' and the 'connected society.'

Mobile devices create not only new forms of knowledge and new ways of accessing it, but also create new forms of art and performance, and new ways of accessing them (such as 'pop' videos designed and sold for iPods). Mobile devices are creating new forms of commerce and economic activity as well. So mobile learning is not about 'mobile' as previously understood, or about 'learning' as previously understood, but part of a new mobile conception of society. (This may contrast with technology enhanced learning or technology supported, both of which give the impression that technology does something to learning.)

In a different sense, ongoing developments on implementing e-Learning, for example in developing the ontologies of learning objects, makes us examine and question how knowledge is organised and interrelated. Here too our notions of knowledge and learning are evolving. It could be argued that the need to organise and navigate through 'bite-sized' pieces of mobile learning content (whether or not as Learning Objects) will also impact on these notions of knowledge and learning and perhaps individual learners will create their own ontologies on-the-fly as they navigate through a personalised learning journey.

One can also focus on the nature of mobility in order to explore the nature of mobile learning. For each learner, the nature of 'mobility' has a variety of connotations and these will colour conceptualisations of mobile education. It may mean learning whilst traveling, driving, sitting, or walking; it may be hands-free learning or eyes-free learning. These interpretations impact on the implementation and hence the definition of mobile learning.

Having earlier discounted technology as a defining characteristic of mobile learning, it may in fact transpire that different hardware and software platforms support rather different interpretations of mobile learning. At the risk of over-simplification, the philosophy behind the Palm ${ }^{\mathrm{TM}}$ based brand of handheld computers (or rather, organisers) initially led to a zero-latency task-oriented interface with only as much functionality as would fit inside the prescribed size of box and this would coax maximum performance out of the processor, the memory, and the battery. Microsoft-based mobile devices by comparison inherited a PC-based interface with considerable latency, making much higher demands on memory, battery, and processor. This dichotomy may be less sharp than it once was, but it could be viewed as underpinning two different interpretations of mobile learning; the former a 'bite-sized' 'just-in-time' version near to the one described above, the latter more like a portable but puny version of 'tethered' e-Learning described above. Similarly, if we were to address whether learning delivered or supported on the current generation of laptop and Tablet PCs should be termed 'mobile learning' then the answer must be 'no.' Learners, and indeed people in general, will carry and use their phones, their iPods, 
or their PDAs habitually and unthinkingly; however, they will seldom carry a laptop or Tablet PC without a premeditated purpose and a minimum timeframe.

Another technical factor, however, may hinder direct comparison with e-Learning. That is the geometry of mobile devices. For several years, proponents of mobile learning have looked for the eventual convergence of mobile phone technologies and handheld computer technologies, creating a basic generic mobile learning platform to which extra (learning) functionality could be added as desired. This might include camera and other data capture, media player capacity, and location awareness using, for example, global positioning systems (GPS). This now looks unlikely to happen and currently the hardware manufacturers and vendors treat their markets as highly segmented and differentiated. This may be due to the nature of the hardware itself. Unlike desktop PCs, where functionality and connectivity can be easily added or subtracted by adding or subtracting internal chips and cards, mobile technologies are fairly monolithic. In the case of laptops, external slots and ports can provide extra connectivity or memory. Anything smaller, such as a handheld or palmtop computer, has one or at best, two slots. This means that a handheld device has only the functionality with which it was made. Manufacturers cannot position and reposition variations on a basic chassis to suit changing markets. Therefore, it is unlikely that we will be able to build a conceptualisation of mobile learning upon the idea of a generic and expandable mobile hardware platform in the way that 'tethered' e-Learning has implicitly been built upon the PC or personal computer platform.

In any case, hardware devices and technical systems are all without exception designed, manufactured, and marketed for corporate, retail, and recreational users. Any educational uses of the devices and the systems are necessarily parasitic and secondary. Therefore, conceptualisations of mobile learning are also constrained by the distorting nature of the technologies and the devices.

The community of practice cohering around mobile learning nevertheless may feel the need for a theory of mobile learning (although in a postmodern era, the role of theory as an informing construct is under threat). Such a theory may be problematic since mobile learning is inherently a 'noisy' phenomenon where context is everything. e-Learning has certainly gained credibility from the work of many outstanding authors. Finding similar beacons for mobile learning may be more challenging and proponents of mobile learning are still struggling to find a literature and a rhetoric distinct from conventional 'tethered' e-Learning.

The discussion so far has implicitly focused on conceptions of mobile learning based on the culture and affordances of developed countries. If we look at the emerging practice of mobile learning based around phones and PDAs in developing countries, especially the poorest, a different picture emerges based on wholly different affordances. The radically different physical infrastructure and cultural environment - including landline telephony, Internet connectivity, electricity, the rarity of PCs, and the relative inability of societies to support jobs, merchandising, and other initiatives based around these prerequisites - has meant that prescriptions for mobile learning are more cautious than in the developed world (Traxler \& Kukulska-Hulme, 2005). It has also meant that mobile phones are now being recognised as the pre-eminent vehicle not only for mobile learning, but also for wider social change (Traxler \& Dearden, 2005). It is entirely possible that the emergence of mobile learning in developing countries will take the evolution of e-Learning along a trajectory that is very different from that in developed countries, where it has been predicated on massive, static, and stable resources. Distance learning will form a significant component of this because of its existing status within the development communities. 
Defining, Discussing, and Evaluating Mobile Learning

Traxler

\section{The Case for Mobile Education}

It is possible to make a strong case for mobile education on 'purist' or theoretical pedagogic grounds. This 'purist' case for mobile learning includes the idea that mobile learning will support a wide variety of conceptions of teaching, and furthermore the ideas that mobile learning are uniquely placed to support learning that is personalised, authentic, and situated.

Different teachers and disciplines will have different conceptions of teaching (Kember, 1997) that they will attempt to bring to education. These conceptions of teaching may vary from ones primarily concerned with the delivery of content, to ones primarily concerned with supporting students learning (i.e., by discussion and collaboration). Mobile learning technologies clearly support the transmission and delivery of rich multi-media content. They also support discussion and discourse, real-time, synchronous and asynchronous, using voice, text and multi-media. Different disciplines, say for example sociology or literature as opposed to engineering, may also require broadly different conceptions of teaching. Distance learning versus site-based/ face-toface education form another alternative axis to the subject axis; distance educators will have their own conceptions of teaching, often influenced by Illich (1971), Freire (1972), and Gramsci (1985).

What are called 'styles of learning' will also exert an influence on how mobile learning is conceptualised. This is currently a contested area (Coffield, Moseley, Hall, \& Ecclestone, 2005), but similar arguments could be advanced about the capacity of mobile learning to fit with the various preferred approaches to learning adopted by different (distance) students at different times.

By personalised learning, we mean learning that recognises diversity, difference, and individuality in the ways that learning is developed, delivered, and supported. Personalised learning defined in this way includes learning that recognises different learning styles and approaches (though perhaps this phrase should not be related too literally to the established literature of 'learning styles,' see for example, Coffield, et al., 2005), and recognises social, cognitive, and physical difference and diversity (in the design and delivery of interfaces, devices, and content). We would argue that mobile learning offers a perspective that differs dramatically from personalised conventional e-Learning in that it supports learning that recognises the context and history of each individual learner and delivers learning to the learner when and where they want it.

By situated learning, we mean learning that takes place in the course of activity, in appropriate and meaningful contexts (Lave \& Wenger, 1991). The idea evolved by looking at people learning in communities as apprentices by a process of increased participation. It can be, however, extended to learning in the field (in the case of botany students for example), in the hospital ward (in the case of trainee nurses), in the classroom (in the case of trainee teachers), and in the workshop (in the case of engineering students), rather than in remote lecture theatres. Mobile learning is uniquely suited to support context-specific and immediate learning, and this is a major opportunity for distance learning since mobile technologies can situate learners and connect learners.

By authentic learning, we mean learning that involves real-world problems and projects that are relevant and interesting to the learner. Authentic learning implies that learning should be based around authentic tasks, that students should be engaged in exploration and inquiry, that students should have opportunities for social discourse, and that ample resources should be available to 
Defining, Discussing, and Evaluating Mobile Learning

Traxler

students as they pursue meaningful problems. Mobile learning enables these conditions to be met, allowing learning tasks built around data capture, location-awareness, and collaborative working, even for distance learning students physically remote from each other.

Mobile learning uniquely supports spontaneous reflection and self-evaluation and the current ePortfolio technologies (see for example, http://www.pebblepad.co.uk/ ) are expected to migrate to mobile devices in the near future.

It is equally possible, however, to make a strong case for mobile education on practical or 'impurist' grounds. This 'impurist' case recognises that learning takes place in a wider social and economic context, and that students must be recognised to be under a range of pressures, most obviously those of time, resources, and conflicting/ competing roles. This is true of distance learning and part-time students. Mobile learning allows these students to exploit small amounts of time and space for learning, to work with other students on projects and discussions, and to maximise contact and support from tutors.

\section{Evaluating Mobile Education}

This section makes the case that the increasing diversity of mobile education and the increasing power, sophistication, and complexity of mobile technologies call into question the adequacy of the conventional repertoire of evaluation techniques based largely around formal, sedentary, and traditional learning. This has always been the case with informal and distance learning anyway. There is a need for a more comprehensive, eclectic, and structured approach to evaluation based on sound and transparent principles. The section briefly elucidates these principles and shows how they can be used to underpin evaluation methodologies appropriate to mobile education.

There are a variety of problems associated with evaluating mobile learning. Perhaps the most fundamental is the problem of defining the characteristics of a 'good' or acceptable evaluation though, of course, the issue of evaluating mobile learning will also take us back to the issue of defining and conceptualising mobile learning. A definition or conceptualisation of mobile learning in terms of learner experience will take evaluation in a different direction from a conceptualisation of mobile learning in terms of hardware platforms. Of course, the categorisation of mobile learning (above) will also influence the practicalities and the priorities of evaluation.

What is not always accepted is that there are no a priori attributes of a 'good' evaluation of learning (to say that there were would be to take an implicitly realist or essentialist position that not every stakeholder would agree with, and would also confront a widely held view that in fact evaluation is a contingent activity). In an earlier work, we tried to outline some tentative candidate attributes of a 'good' evaluation (Traxler, 2002), but we also identified the reasons why evaluation of mobile learning is unusually challenging. Briefly some of these attributes were that a 'good' evaluation could be:

- Rigorous, meaning roughly that conclusions must be trustworthy and transferable

- Efficient, in terms of cost, effort, time, or some other resource

- Ethical, specifically in relation to the nuances of evolving forms of provision, in terms of standards from

o legal 
Defining, Discussing, and Evaluating Mobile Learning

Traxler

0

to normative

- Proportionate, that is, not more ponderous, onerous, or time-consuming than the learning experience or the delivery and implementation of the learning itself (bearing in mind earlier remarks about the learners' experiences of mobile learning)

- Appropriate to the specific learning technologies, to the learners, and to the ethos of the learning - ideally built in, not bolted on

- Consistent with the teaching and learning philosophy and conceptions of teaching and learning of all the participants

- Authentic, in accessing what learners (and perhaps teachers and other stakeholders) really mean, really feel, and sensitive to the learners' personalities within those media

- $\quad$ Aligned to the chosen medium and technology of learning

- Consistent across:

o different groups or cohorts of learners in order to provide generality

o time, that is, the evaluation is reliably repeatable

o whatever varied devices and technologies are used

The last of these attributes is challenging in mobile learning, since the technologies are changing at an exceptional pace and consequently reaching any understanding of underlying issues is difficult. Some of the others are more subtle. Some issues around ethics have been explored elsewhere recently (Traxler \& Bridges, 2004): mobile learning continues to evolve however.

A recent review of practice in the evaluation of mobile learning (Traxler \& Kukulska-Hulme, 2005) suggests that not many accounts (none were distance learning anyway) articulated an explicit position on pedagogy or epistemology. They seldom cited any works from the literature of evaluation or any works from the literature of the ethics of evaluation. They seldom, if ever, mentioned any ethical issues in relation to their evaluation. Most accounts cited focus groups, interviews, and questionnaires as their elicitation instruments. Some used observation and some used system logs. A few accounts mentioned several techniques and were triangulated, but most accounts used only one or, at most, two techniques. None of these elicitation techniques were particularly consistent with mobile learning technologies. And all accounts of such evaluations assumed that the evaluators were told the truth by subjects (that is, learners and teachers); Hopefully, those involved in mobile distance learning evaluation will learn from this critique.

Clearly, there are problems with the epistemology and ethics of evaluating mobile learning; there are also challenges in developing suitable techniques to gather, analyse, and present evaluation. Nevertheless, the credibility of mobile, including distance, learning as a sustainable and reliable form of educational provision rests of the rigour and effectiveness of its evaluation.

\section{Mobile Education in Universities and Colleges}

Mobile education, however innovative, technically feasible, and pedagogically sound, may have no chance of sustained, wide-scale institutional deployment in higher education in the foreseeable future, at a distance or on site. This is because of the strategic factors at work within educational institutions and providers. These strategic factors are different from those of technology and 
pedagogy. They are the context and the environment for the technical and the pedagogic aspects. They include resources (that is, finance and money but also human resources, physical estates, institutional reputation, intellectual property, and expertise) and culture (that is, institutions as social organisations, their practices, values and procedures, but also the expectations and standards of their staff, students and their wider communities, including employers and professional bodies).

Implementing wireless and mobile education within higher education must address these social, cultural, and organisational factors. They can be formal and explicit, or informal and tacit, and can vary enormously across and within institutions. Within institutions, different disciplines have their own specific cultures and concerns, often strongly influenced by professional practice in the 'outside world' - especially in the case of part-time provision and distance learning. Because most work in mobile learning is still in the pilot and/ or trial phase, any explorations of wider institutional issues are still tentative (Traxler, 2005; JISC, 2005) but it points to considerable hurdles with infrastructure and support.

\section{Conclusions}

This has been a very wide-ranging attempt to explore the nature and possibilities of mobile learning. It draws together much existing work, but this is still a relatively immature field. It has not explored the actual technologies or pedagogies in any detail and has sought to define questions for discussion rather than provide answers for what might in fact be premature or inappropriate questions. It is too early to describe or analyse the specifics of mobile learning for distance learning since the field, as a whole, is new and accounts are relatively sparse. The synergy between mobile learning and distance learning, however, holds enormous potential.

\section{References}

Attewell, J., \& Savill-Smith, C. (Eds.) (2003). Learning with Mobile Devices: Research and development. MLEARN '03 Book of Papers. London: Learning and Skills Development Agency.

Brown, B., \& Green, N. (2001). Wireless World: Social and interactional aspects of the mobile age. New York: Springer-Verlag.

Chen, Y. S., Kao, T. C., \& Sheu, J. P. (2003). A mobile learning system for scaffolding bird watching learning. Journal of Computer Assisted Learning, 19(3), 347-359.

Coffield, F., Moseley, D., Hall, E., \& Ecclestone, K. (2004). Should we be using learning styles? What research has to say to practice. London: Learning and Skills Research Centre.

Freire, P. (1972). Pedagogy of the oppressed. London: Penguin.

Gayeski, D. (2002). Learning Unplugged - Using mobile technologies for organisational and performance improvement. New York: AMACON - American Management Association.

Gramsci, A. (1985). Selections from cultural writings. London: Lawrence \& Wishart. 
Defining, Discussing, and Evaluating Mobile Learning

Traxler

Griswold, W., Boyer, R., Brown, S., Truong, T., Bhasker, E., Jay, G., \& Shapiro, B. (2002).

Using mobile technology to create opportunistic interactions on a university campus. San Diego, CA.: Computer Science and Engineering, University of California, San Diego.

Hackemer, K., \& Peterson, D. (2005) Campus-wide handhelds. In A. Kukulska-Hulme \& J. Traxler (Eds.) Mobile Learning: A handbook for educators and trainers. London: Routledge

Hewson, C., Yule, P., Laurent, D., \& Vogel, C. (Eds.) (2003). Internet Research Methods: A practical guide for the social and behavioural sciences (New Technologies for Social Research series). London: Sage.

Illich, T. (1971). Deschooling society. London: Marion Boyars.

Katz, J. E., \& Aakhus, M. (Eds.) (2002). Perpetual Contact - Mobile Communications, Private Talk, Public Performance. Cambridge, UK.: Cambridge University Press.

Kember, D. (1997). Reconceptualisation of Research into University Academics' Conceptions. Learning and Instruction, 7(3), 255-275.

Kneebone, R. (2005). PDAs for PSPs. In A. Kukulska-Hulme \& J. Traxler (Eds.) Mobile Learning: A Handbook for Educators and Trainers (pp. 106-115). London: Routledge

Kukulska-Hulme, A., \& Traxler, J. (2005). Mobile Learning: A Handbook for Educators and Trainers. London: Routledge

Kukulska-Hulme, A., \& Traxler, J. (in press). Learning Design with Mobile and Wireless Technologies. In H. Beetham \& R. Sharpe (in press). Rethinking Pedagogy for the Digital Age London: Routledge

JISC (2005). Innovative Practice with e-Learning. Bristol, UK.: Joint Information Services Committee

Lave, J., \& Wenger, E. (1990). Situated Learning: Legitimate peripheral participation. Cambridge, UK.: Cambridge University Press.

Lundin, J., \& Magnusson, M. (2003). Collaborative learning in mobile work. Journal of Computer Assisted Learning, 19(3), 273-283.

O'Malley, C., \& Stanton, D. (2002). Tangible Technologies for Collaborative Storytelling. Proceedings of MLEARN 2002, European Workshop on Mobile and Contextual Learning, June 20-21, 2002 (pp. 63-64). Birmingham, UK.: University of Birmingham,

Pasanen, J. (2003). Corporate Mobile Learning. In H. Kynaslahti \& P. Seppala (Eds.) Mobile Learning (pp. 115-123). Helsinki: IT Press.

Perry, D. (2003). Handheld Computers (PDAs) in Schools. Coventry, UK.: BECTa. 
Defining, Discussing, and Evaluating Mobile Learning

Traxler

Pinkwart, N., Hoppe, H. U., Milrad, M., \& Perez, J. (2003). Educational scenarios for cooperative use of Personal Digital Assistants. Journal of Computer Assisted Learning, 19(3), 383391.

Polishook, M. (2005) Music on PDAs. In A. Kukulska-Hulme \& J. Traxler (Eds.) Mobile Learning: A Handbook for Educators and Trainers. London: Routledge

Sariola, J. (2003). The Boundaries of University Teaching: Mobile Learning as a Strategic Choice for the Virtual University. In H. Kynaslahti \& P. Seppala (Eds.), Mobile Learning (pp. 71-78). Helsinki: IT Press.

Seppala, P., \& Alamaki, H. (2003). Mobile learning in teacher training. Journal of Computer Assisted Learning, 19(3), 330-335.

Smordal, O., \& Gregory, J. (2003). Personal Digital Assistants in Medical Education and Practice. Journal of Computer Assisted Learning, 19(3), 320-329.

Traxler, J. (2002). Evaluating m-learning. Proceedings of MLEARN 2002, European Workshop on Mobile and Contextual Learning, June 20-21 (pp. 63-64). Birmingham, UK.:

University of Birmingham,

Traxler, J. (2005) Institutional Issues: Embedding and Supporting. In A. Kukulska-Hulme, \& J. Traxler (Eds.) Mobile Learning: A Handbook for Educators and Trainers (pp. 173-188). London: Routledge

Traxler, J., \& Bridges, N. (2004). Mobile Learning - The Ethical and Legal Challenges. Proceedings of MLEARN 2004, Bracciano, Italy, June 2004.

Traxler, J. \& Dearden, P. (2005) The Potential for Using SMS to Support Learning and Organisation in Sub-Saharan Africa. Proceedings of Development Studies Association Conference, Milton Keynes, September 2005

Traxler, J., \& Kukulska-Hulme, A. (2005). Mobile Learning in Developing Countries. In G. Chin (Ed.) A report commissioned by the Commonwealth of Learning. Vancouver, BC.:

Commonwealth of Learning.

Traxler, J., \& Kukulska-Hulme, A. (2005) Evaluating Mobile Learning: Reflections on Current Practice. Proceedings of MLEARN 2005, October 25-28, Cape Town, South Africa.

Vuorinen, R., \& Sampson, J. (2003). Using mobile Information Technology to Enhance Counselling and Guidance. In H. Kynaslahti \& P. Seppala (Eds.) Mobile Learning (pp. 63-70). Helsinki: IT Press.

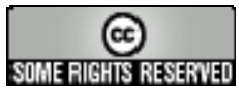

